\title{
Strategy Design to Improve the Implementation of Supply Chain Management in Food SMEs
}

\author{
Agustina Windaryanti, M. Dachyar*, and Farizal \\ Industrial Engineering Department, Universitas Indonesia
}

\begin{abstract}
Food and beverage industry serves as one of the primary industries by the Ministry of Industry for industrial development plan until 2035. To improve the competitiveness of food SMEs, the strategy of implementing supply chain management is designed. The purpose of this research is to obtain strategy recommendations for the implementation of supply chain management in food SMEs. The literature study was conducted to find out the criteria, sub-criteria, and strategies that need to be implemented in improving the supply chain management of the food SMEs. Analytical Network Process (ANP) method is used to find the weight of criteria, sub-criteria, and strategy of implementing supply chain management. Criteria, sub-criteria, and strategies are judged by seven experts. This research obtained five criteria, twelve sub-criteria, and twentythree strategies for the implementation of supply chain management. The result of data processing shows strategy that has the highest weight is to coordinate the logistics department with other functions in the company.
\end{abstract}

\section{Introduction}

Best supply chain management practice in food and beverage industry will increase the industry's competitiveness level. Problems encountered in the food and beverage industry is the supply chain. Losses due to inefficient supply chains in the food and beverage industry reached 86.6 trillion rupiah [1].

\section{Literature Review}

Operations management $(\mathrm{OM})$ is a management area that handles supervision, design, production, and reproduction of products and services that improves the company's efficiency [2]. A supply chain consists of all entities involved in the process of meeting the needs of consumers, either directly or indirectly. Supply chain members are not just manufacturing and supplier companies, but also retailers and even consumers themselves [3]. The food supply chain is different from the supply chain of other products. The fundamental difference between the food supply chain and other supply chains is the persistent and significant change in the quality of food products throughout the entire supply chain to the point of final consumption [4].

\footnotetext{
* Corresponding author: mdachyar@yahoo.com
} 
The previous study, research involving SMEs in Turkey, the implementation of SCM can lower inventory levels, decrease production time, increase flexibility, demand forecast accuracy, cost savings and accurate resource planning [5].

Multi-criteria decision making (MCDM) has classified into two categories: multiattribute decision making (MADM) and multi-objective decision making (MODM) decisions [6]. The MADM technique involves very much human participation and judgment. MADM consists of methods of ELECTRE, Technique for Order of Preference by Similarity to Ideal Solution (TOPSIS), AHP, ANP, Preference Ranking Organization Method for Enrichment Evaluation (PROMETHEE), MAUT, and others. MODM consists of goal programming and genetic algorithm.

Analytical Network Process (ANP) is a framework used to solve problems related to decision making without having to make assumptions about the relation of dependence and the interrelation of elements with different levels and also the reliance of elements in the same level [7]. An important aspect of pairwise comparisons is mutual property. When one element has a ratio $\mathrm{x}$ times more dominant than the other concerning the given property, the inverted comparison do where the lower element has a reciprocal value of $1 / \mathrm{x}$ [8]. The consistency validation of pairwise comparisons is required. Consistency ratio value should not be more than 0.1 for pairwise comparison is said to be consistent [8]. ANP has been used previously in the area of fuel subsidy policy elections [9], supplier selection, and location selection [10].

\section{Research Methodology}

Data is processed by using the ANP method steps, as follow: (1) identification of criteria, sub-criteria, and strategies; (2) criteria, sub-criteria, and strategies selection; (3) determination of the interdependence relationship between criteria, sub-criteria, and strategies; (4) model construction based on dependency relationship; (5) construct pairwise comparisons questionnaire; (6) construct supermatrix; (7) obtaining the weight of strategies.

Seven experts judged criteria, sub-criteria, and strategies. Results of judgment calculated using geometric mean and selected five criteria, twelve sub-criteria, and twenty-three strategies affecting the improvement of SCM implementation. The criteria are food traceability [11], collaboration [12], information [13], flexibility [12] [14], and internal organization [15]. Twelve sub-criteria are regulation, quality and food safety [11], logistics and distribution planning, supplier management, inventory management, demand planning, production planning [12], information sharing [13], product flexibility [14], human resources management, knowledge management [15], top management commitment [16].

The twenty three strategies are registering to The National Agency of Drug and Food Control of Republic of Indonesia (A1), registering to halal certificate (A2), providing clear traceability information (production date and expiration date) until it arrives to the consumer (A3), performing hygienic supply chain management (A4), considering the quality of the packaging (A5) [17], to coordinate the logistics department with other functions in the company (A6) [18], to conduct assessment and monitoring to suppliers based on cost, quality and delivery performance (A7) [19], building long-term relationships with suppliers based on trust (A8), collaborating with suppliers for better inventory management (A9) [20], implementing Just In Time (JIT) to reduce inventory (A10) [12], using information technology throughout the supply chain to inform demand and production information to reduce the number of finished goods (A11), identifying factors (promotions, discounts, etc.) that affect the number of requests and assess the influence of each factor on future consumer demand (A12), comparing and analyzing real demand and demand forecasts to improve the level of accuracy of future demand forecasts (A13), using a production planning system (A14), sharing information regularly (A15), relevant, accurate, and complete information 
(A16), ability to standardize the product (A17) [21], investing in Research and Development process for product innovation (A18) (Tummala \& Schoenherr, 2011, employee training programs (A19), cooperation among employees (A20), knowledge sharing in the various functions of the supply chain (A21), the acquisition of knowledge from people who have experienced in a part of the supply chain (A22), creating Standard Operating Procedures (SOP) throughout the supply chain (A23) [22]. Experts judged the linkages from one element to others. The construction of ANP model shown in Fig.1.

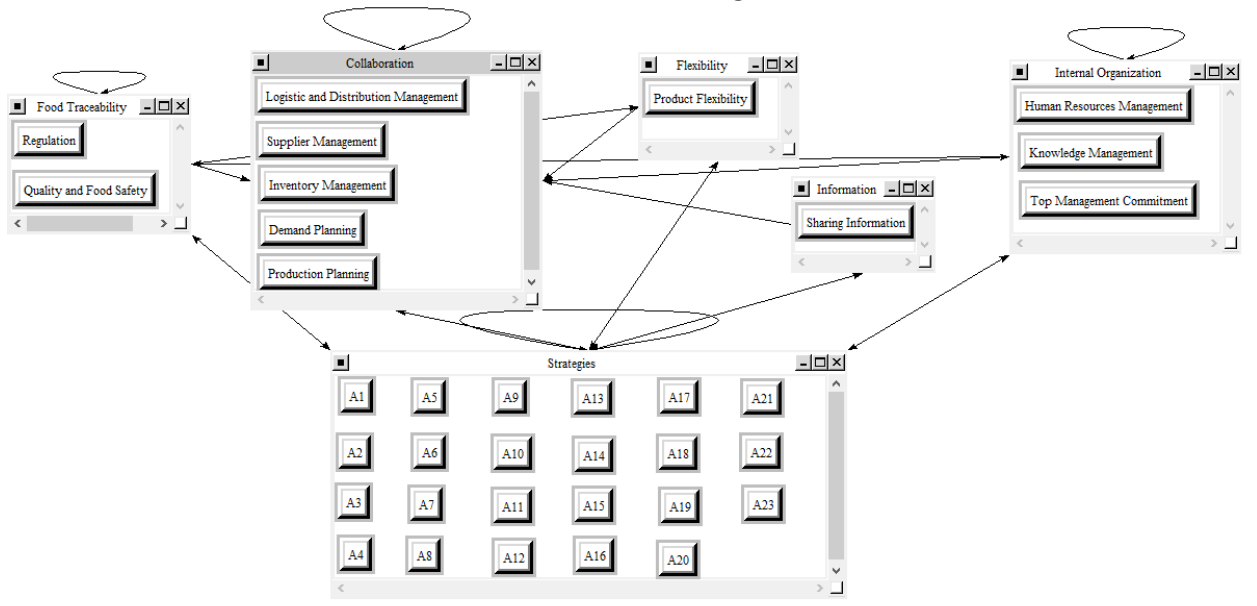

Fig. 1. The ANP Model of Strategy to Improve the Implementation of SCM

The inconsistency value of all priority vectors in this study is less than 0.1 so that the ANP model is consistent and valid. The transformation from unweighted supermatrix, to weighted supermatrix, limited matrix generated the criteria, sub-criteria and strategies weight.

\section{Results and Discussion}

\subsection{Criteria and Sub-Criteria Weight}

The highest to lowest criteria's weight in a row namely, collaboration (0.562), food traceability (0.282), flexibility (0.076), internal organization (0.049) and information (0.031). The highest weight indicates that collaboration is the most important criteria in the improvement of the implementation of SCM system in food SMEs because collaboration starting from raw material purchase to the distribution of finished goods is the essential thing for SMEs to survive. Food traceability is the second most important criteria because the food industry has characteristics such as a relatively short lifetime and direct effect to human health and safety, so it is essential to know the date of expiration for the consumer.

The highest weight of sub-criteria is quality and food safety (0.232), followed by logistics and distribution planning $(0.207)$, production planning $(0.136)$, inventory management (0.096), product flexibility (0.076), demand planning (0.076), regulation (0.05), supplier management (0.047), top management commitment (0.029), knowledge management (0.002), and human resources management (0.018).

\subsection{Strategies Weight}


Coordinating the logistics department with other functions in the company has the highest weight / A6 (0.183). The increasing of demand results in the highest strategy weight is A6 $(0.242)$. The challenge to innovate the food products results in of the highest strategy weight is A6 (0.191).

\section{Conclusion}

This research obtained five SCM criteria, twelve sub-criteria, to find the best SCM strategy in Food SMEs. The most important criteria for implementing SCM is the collaboration, and the most critical sub-criteria is food traceability. Collaboration with other companies or suppliers will increase the competitiveness to lead the market. To improve SCM performance, the food SMEs management can implement these priorities: (1) coordinate the logistics department with other functions in the company has the largest weight, (2) use production planning system, (3) register to The National Agency of Drug and Food Control of Republic of Indonesia; (4) consider the quality of the packaging; and (5) provide clear traceability information (production date and expiration date) until the product arrives at the consumer.

This research funded by Universitas Indonesia - PITTA 2018

\section{References}

1. R. A. Mulyo, Food Loss and Food Waste Rice Comodity in Indonesia (2016).

2. R. K. Jain, H. Nemade, G. H. Yadav, and P. Sehgal, Int. J. Adv. Eng. Technol., (2013).

3. S. Chopra and P. Meindl, Supply Chain Management : Strategy, Planning, and Operation (2015).

4. R. Akkerman, D..V.Meer, and D.P. Van Donk, Int. J. Prod. Res., 48, 3475-3492 (2010).

5. S. C. Lenny Koh, M. Demirbag, E. Bayraktar, E. Tatoglu, and S. Zaim, Ind. Manag. Data Syst., 107, 103-124 (2007).

6. C.-L. Hwang and K. Yoon, Multiple Attribute Decision Making: Methods and Applications A State-of-the-Art Survey, 58-191 (1981).

7. T. L. Saaty, J. Syst. Sci. Syst. Eng., 13, 129-157 (2004).

8. T. L. Saaty and M. Sodenkamp, Int. J. Appl. Decis. Sci., 1, 24 (2008).

9. I. Hardiati, M. Dachyar, and Yadrifil, Int. J. Appl. Eng. Res., 10 (2015).

10. M. R. Khadivi and S. M. T. Fatemi Ghomi, Waste Manag., 32, 1258-1265 (2012).

11. T. Bosona and G. Gebresenbet, Food Control, 33, 32-48 (2013).

12. V. M. R. Tummala and T. Schoenherr, Int. J. Logist. Syst. Manag., 8 (2011).

13. E. Hassini, C. Surti, and C. Searcy, Int. J. Prod. Econ, 140, 69-82, (2012).

14. J. H. M. Manders, M. C. J. Caniëls, and P. W. T. Ghijsen, J. Purch. Supply Manag., 22, 181-195 (2016).

15. P. Beske, A. Land, and S. Seuring, Int. J. Prod. Econ., 152, 131-143 (2014).

16. R. . Singh, R. Kumar, and R. Shankar, Int. J. Manuf. Res., 7, 165-180 (2011).

17. M. Bourlakis, G. Maglaras, E. Aktas, D. Gallear, and C. Fotopoulos, Int. J. Prod. Econ., 152, 112-130 (2014).

18. C. Basnet, Manag. Res. Rev., 36, 153-172 (2012). 
19. N. Banaeian, H. Mobli, B. Fahimnia, I. E. Nielsen, and M. Omid, Comput. Oper. Res., 89, 337-347 (2018).

20. S. S. Padhi, R. K. Pati, and A. Rajeev, J. Clean. Prod., (2018).

21. R. K. Singh, Meas. Bus. Excell., 17, 80-97 (2013).

22. C. Lin, C. Kuei, and C. Kang-Wei, Int. J. Oper. Prod. Manag., 33, 347-370 (2013). 